\title{
Games and the Future of Man. Gamification as a Transhumanist Program
}

\author{
Kamil Kleszczyński \\ Ph.D. Student, University of Zielona Góra (Zielona Góra, Poland) \\ E-mail: kamil.kleszczynski@gmail.com \\ https://orcid.org/0000-0002-1724-6854
}

This article deals with the question of how games can affect people's future. The author claims that the main mechanism of this influence is gamification. The features of this process make it a way of preparing people to function in reality created as a result of the development of digital technologies. It is possible to indicate three main areas of the realization of this function of gamification. The first one is progressive virtualization, resulting in the disappearance of reality and multiplication of man's ways of existence. Gamification teaches how to function in these conditions. The second is the need for constant auto-creation, resulting from the rapidly changing economic and social conditions. Gamification works well here, which can be seen, for example, when it connects with self-tracking. The third is the disappearance of the meaning of life, which is the result of devaluation of various activities in the world of constant change and technical progress satisfying more and more human needs. Here gamification works as a meaning generator, a kind of prosthesis for activities, the performance of which has already lost its external justification. These three aspects form the basis for the recognition that gamification is a kind of transhumanist program that binds human development to technological development.

Keywords: transhumanism, gamification, virtualization, auto-creation, utopia, video games

Received: September 19, 2019; accepted: October 22, 2019

Future Human Image, Volume 12, 2019: 53-63.

https://doi.org/10.29202/fhi/12/4

\section{Introduction}

Gamification is understood in different ways. Some refer to this term only in relation to certain practices that can be described as: "the use of design elements characteristic for games in non-game contexts" [Deterding et al., 2011: 5]. Others use this term to describe the social and cultural impact of digital games. In this approach, gamification is understood as "the process of a total permeation of our society with methods, metaphors, values and attributes of games (...)" [Fuchs, 2014: 119-120]. Combining these two approaches, I propose to recognize that gamification is a mechanism of such a transformation of elements or the whole of culture that is consistent with the rules of game creation. Today, this mechanism is driven primarily

(C) Kleszczyński, Kamil, 2019 
by the development of video games, therefore concerns not only the expansion of games, but also the process of digitization. At the same time, gamification in the above sense is a starting point for attempts to understand the impact that games have on the reality in which people live and on people themselves.

Questions about the directions of the changes that man will undergo are posed today within the framework of transhumanist reflection. However, the indication of changeability as the basis of humanity is much older. In the work considered a manifesto of humanism, Giovanni Pico della Mirandola wrote that the greatness of human nature lies in the fact that it is undefined. Man, as the creator of himself, can be anything he wants. It is up to him whether he degrades himself to the level of an animal or plant, or whether, on the contrary, he rises to the level of a divine being [Pico della Mirandola, 1967: 138-140]. Of course, such a vision is always resisted by those who want to close human nature in a certain form that can serve as a normative model.

Nowadays, however, one cannot turn one's eyes away from the fact that man is a project. In a world in which technology takes on subjective forms - in the form of artificial intelligence or social robots - and colonial approaches to other organisms are rejected, the position of man must change and undergoes change. In the context of these transformations, not only questions about the future of mankind are formulated, but also postulates of its conscious shaping. This is expressed especially in the views of the representatives of transhumanism. Piotr Zawojski defined it as: “(...) an intellectual, philosophical and cultural movement proposing a vision of a posthuman being who, by means of neurotechnological, biotechnological and nanotechnological tools, seeks to overcome human limitations. This can be achieved through the use of vaccines, implants, prostheses, plastic surgery, but also more futuristic solutions, such as brain implants, mind uploading, nano-robots" [Zawojski, 2018: 92]. The catalogue of technologies considered by the transhumanists is not closed and includes both those already known and those being designed. In the general sense, however, it is all about breaking the border between technology and man, laying the foundations for their combination.

Gamification, in which games are a kind of vehicle between the analogue and digital aspects of culture ("understandable" and applicable both by man and computer), is a potential tool of transhumanism. By managing human activity through a set of clear rules allowing for its algorithmization, it enables "connection" to a computerized network. It also prepares to function in a world transformed by digital technology. It seems that gamification is a response to three changes in particular: 1) Virtualization, 2) Continuous social and economic changeability, forcing the necessity of undertaking the process of auto-creation all the time, 3) Continuous obsolescence of the sense of a given action in the world of continuous change. In such an approach, gamification can be considered as an operating system for a transhuman being, improving or even enabling its operation in the new world.

\section{Gamification and virtualisation of reality}

\subsection{Disappearance of reality}

One of the most important problems of contemporary man is the disappearance of reality. Jean Baudrillard most probably showed this most emphatically, and he recognized that we live today in the world of simulacra, i.e. signs that have broken away from their points of reference, from reality. They create a new reality - hyper-reality. He wrote: "the era of simulation is 
inaugurated by a liquidation of all referentials - worse: with their artificial resurrection in the systems of signs, a material more malleable than meaning, in that it lends itself to all systems of equivalences, to all binary oppositions, to all combinatory algebra. It is no longer a question of imitation, nor duplication, nor even parody. It is a question of substituting the signs of the real for the real, that is to say of an operation of deterring every real process via its operational double, a programmatic, metastable, perfectly descriptive machine that offers all the signs of the real and short-circuits all its vicissitudes. Never again will the real have the chance to produce itself" [Baudrillard, 1994: 2]. We must therefore learn to live in a world that is separated from reality.

It is not an easy task. Contemporary man pays a huge price for creating a world so detached from reality. Zofia Rosińska pointed out that the culture resulting from the spread of the Internet makes it difficult to distinguish between what is real and what is fictitious. This leads to the spread of mental disorders, led by depression, which becomes a social disease. The researcher stated that it is the separation from reality, or derealisation, that is to blame for this: she used the term proposed by Antoni Kępiński [Rosińska, 2015]. It seems that the disappearance of reality will continue, the main factor of which will be virtualization. It is worth considering the role played by gamification here.

By transforming various situations into games, gamification tames the human being with progressive virtualization of the surrounding world and his own functioning in this new world. Its basic function, i.e. the melting of play and work, breaks an important boundary. Virtual game, which was used to train skills realized later in reality, was a simulation of "real" activities. Such a distinction loses its meaning when, for example, a surgeon does not practice on a computer an action performed by himself, but controls a robot that at some point already operates on a real one, and not on a virtual organ. Virtualization is therefore a very important change in the reality of contemporary man, and gamification is strongly connected with it. The analysis of this relation should be started from explaining what is the starting point of virtualization — virtuality.

\subsection{Virtuality and virtualization}

There are three basic ways to understand the word "virtual". In the common understanding, the word seems to mean unreality, but it is related to the immaterial character of what is virtual. The philosophical meaning of virtuality derives from scholastic philosophy, where virtual was what existed potentially and not actually. Nowadays, the word "virtual" appears most often in relation to a specific information technology. Virtual Reality (VR) is a technology whose intensive development evokes a lot of emotions. Its well-known definition is: "Virtual Reality is the use of computer technology to create the effect of an interactive three-dimensional world in which the objects have a sense of spatial presence" [Bryson, 1998: 4]. The first examples of technology understood in this way were the projects of the computer artist Myron W. Krueger from the 1960s and 1970s. Since then, with the development of technology, its accessibility has also increased. There are many devices using VR on the market, and it is also available in special salons and at various educational stands. Applications, videos available on the Internet and affordable cardboard enclosures that fit into many smartphone models make the technology practically universally available. This, together with the forecasts of intensive development of this market, suggests that the future will be increasingly saturated with various applications of virtual reality. 
This makes it necessary to reflect on the changes in human existence, which will take place in VR to some extent. This is visible in the newer definition, in which the starting point is no longer technology (taken at a given moment of its development), but function, which is revealed from the perspective of the user. Steven M. LaValle considered that VR is: "Inducing targeted behavior in an organism by using artificial sensory stimulation, while the organism has little or no awareness of the interference" [LaValle, 2019: 1]. Lack of consciousness means here a kind of "stupidity" of the organism so that it has a feeling that it is in another world or that the virtual world is natural [LaValle, 2019: 3]. This definition is so broad that it allows to search for virtuality at the very beginning of art, which, after all, has always - to a greater or lesser degree - deceived the senses of the viewer and transferred it to "another" world. Such universality is an advantage in the new digital reality, one of the main features of which is virtualization.

This issue was discussed by Pierre Lévy, who considered that the genesis of the virtualization process can be observed in the sphere of information and communication. Digital codes are almost independent of specific spatial and temporal coordinates. Although they are located in a given physical place (for example on a server), they also exist virtually everywhere they can be called. The virtual world as a set of numerical codes is a set of potential images, while its appearance on the screen, its projection immersed in the potential world updates this potential through detailed application [Lévy, 2002: 379]. Lévy found that this process went far beyond the information and communication sphere, transforming our physical presence, social interactions and economic activity. This is achieved mainly through deterritorialization, understood as an escape from "it", "here" and "now" [Lévy, 1998: 30]. Virtualization understood in this way binds the triple meaning of virtuality: it creates an alternative situation to "ordinary" reality, allows for the reality of potential entities and places the process in the actual IT context.

\subsection{Games and virtuality, gamification and virtualization}

Video games accompany virtuality and virtualization from the beginning. First of all, it was the commercial success of the games that enabled the intensive development of the technology used in them. The development of computer graphics in particular can be indicated here, in which an important trend was better and better representation of reality, but also interfaces and motion controllers. In turn, this was what the researchers developing VR were looking for. They still often adapt software originally developed for games [LaValle, 2019: 47]. Secondly, games taught people how to function in a virtual environment. For example, the experience of falling into the abyss for the digital natives is no longer known, unlike their ancestors, only from dreams. LaValle noticed that: "Those who have spent many hours and days in front of large screens playing first-person shooter games apparently experience less vection when locomoting themselves in VR" [LaValle, 2019: 59]. It can therefore be considered that games play a double role in the development of virtual reality. They serve as a driver for technology development, but also prepare society for the changes it brings about.

Gamification is a significant development of this process. While games have created situations similar to those in VR, gamification can create identical situations. A virtualized situation has at least three features in common with a situation of gamification. First of all, the world in both situations is artificially created by the designer (in gamification it is also often a digital world). Secondly, the element constructing this world — updating it — is the involvement of the subject - the immersion based on the rejection of the consciousness of the 
untrue (in the traditional understanding) of this world. Thirdly, both situations are replayable in the sense that their potential can be realized many times in very different scenes, depending on the subject and circumstances. To sum up, gamification and virtualization are parallel processes that can interact with each other.

\section{Auto-creation through gamification}

\subsection{Philosophical context of auto-creation}

An important promise of the transhumanists is that one of the main directions of technology development will be to offer more and more control over the quality of one's own life, including control and development of oneself. Individual development, understood as a consciously targeted change, must be based on two foundations. The first is awareness of the current and desired state of the individual. The second is the ability to make such a change, i.e. to have a causal power in relation to one's own actions. We find both these foundations at the source of the wisdom of the West, in the famous Delphic maxims. One of them sounds: “control yourself" (gr. $\alpha \rho \gamma \varepsilon \sigma \varepsilon \alpha v \tau o v)$. Another, popularized by Socrates (engraved on the front of the temple in Delphi, not on the stele in front of it, but counted as a maxim), proclaims:

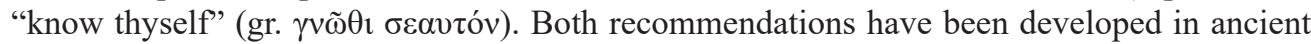
philosophy. Self-knowledge is nowadays associated primarily as the essence of the phrase proposed by Socrates, a significant moment of departure from the philosophy of nature and a focus on anthropological and ethical reflection [Reale, 2005: 311-317]. On the other hand, self-control became a programmatic recommendation of stoicism.

Self-knowledge and self-control are combined in the postulate of taking care of oneself. The connection between them has the character of implications. The better we know ourselves, the better we understand what is good for us, what is bad and - what is obvious - we choose the former. In this choice, however, the ability to control oneself is realized. Nowadays, taking care of oneself is manifested in intensive promotion of a healthy lifestyle: practising sport, proper diet, etc. In fact, it is the implementation of a programme funded on the idea of healthism [Crawford, 1980]. The most important assumptions of its concept are the recognition of health as the highest value, but also the transfer of the duty to take care of it from the state to the individual.

\subsection{Gamification and self-tracking}

Digital technology not only enables instant and universal access to information on specific aspects of behaviour within a wide range of self-care activities. Its most important function is to evaluate such activities. This is reflected in the practices of self-tracking, which is a collection of methods of monitoring and analysis of body functions, through applications operating in various types of devices, such as smartphones or special bands. Of course, such practices began mainly in the health sector, both in the promotion of a healthy lifestyle and in professional medicine - in cardiological monitoring or telemedicine. However, at present, they concern very different areas of everyday life, such as time organization, travel or social communication. Around such activities a social movement has been established: Quantified Self. It was founded by two editors of "Wired" magazine: Gary Wolf and Kevin Kelly. Movement representatives are not only passionate about the possibility of collecting 
various data about themselves, but also about the possibility of using it in practice to improve their behaviour, improve their efficiency, control their health or eliminate harmful habits. As Michał Wróblewski noted: "Behind QS lies a specific ideology, which is a combination of the Delphic maxim "know thyself" with modern technologies of data collection and analysis. (...) however, it is not only about getting to know each other, but also about improving one's own body. Data collection is designed to fight bad habits such as unhealthy diet or lack of exercise" [Wróblewski, 2016: 7]. Therefore, the movement realizes the idea of transhumanism, engaging technological development in human development, while relying on ancient wisdom.

Gamification is easily applied in the self-tracking concept. Their common ground is quantification. Obtained data on the activity of the organism must be processed in such a way that they can perform a cognitive function in relation to the activities undertaken by the individual. In a simple example: running a certain number of kilometers allows to burn a certain number of calories. However, this information must be used for a second purpose: development. Here, gamification, with its levels, rankings, prizes, points and other forms of feedback from games, is an ideal tool for motivating and evaluating progress.

Strengthening auto-creative human capabilities is not only possible in the real world. Since man's life is increasingly taking place simultaneously in two spaces: physical and digital, he also takes care of his representation in the network. Many people strive to develop their profiles in social media even at the expense of being active in the real world. Building a digital identity can also take the form of a visual avatar. Research on this type of auto-creation is developing intensively [Hayles, 1999; Kania, 2018; Sidey Myoo, 2013]. Gamification in this context functions primarily at a higher level — i.e. the virtualization of reality in general — which I discussed in the previous section. It teaches how to construct and play various characters, it allows the player to identify with them. Getting used to working in digital incarnations, it trains in functioning outside the body.

\section{Gamification as a meaning generator}

\subsection{Motivation and meaning of life}

An extremely popular term today is: "motivation". The number of websites, guides or trainings offering better and better ways to motivate oneself and others to various tasks is growing exponentially. Areas that are becoming more and more popular, such as coaching and mentoring, are largely based on the assumption that proper motivation of an individual is the key to extracting his or her full potential, thus allowing him or her to fulfil himself or herself in various areas of life. Such a situation indicates the source of demand - depletion of "natural" motivation resources. Gamification perfectly matches this demand. The way in which players can motivate themselves to perform tasks that objectively do not seem to bring any benefits is often astonishing for an external observer.

The deficit of motivation is based on a combination of phenomena causing a sense of meaninglessness of life in contemporary man and the impossibility of setting his goal. The political and social crisis and exponential technological progress (both, of course, interlinked) have made the world an unprecedented changeable place. The landscape in which we have to make choices about the purpose of our journey in life has become foggy, fluid and increasingly deceptive. This causes constant uncertainty and obsolescence in the value of the actions taken by the individual. Playing games can be a remedy for this state of affairs. It offers a specific 
"overlay" for everyday life, constituting a potential skeleton of activities. If we are not able to rely on reality, we use a prosthesis.

The sense of human life, motivation to act - have a clear philosophical context. Jan Hartman noted that the meaning of life as such has only been dealt with recently, since we began to question it. However, it should be treated as a traditional philosophical problem, because already ancient thinkers intensively considered the issue of closely related to it good life. "For there is an obvious correlation between the question about the meaning, meaningfulness of life, and the question about the proper and well lived life. Although these problems are not the same, they overlap. If we assume that at least sometimes the life of a person has some sense, it is when it is good, sensible, and therefore not just as experienced as it was. So who would know the answer to the question how to live a good life, will at the same time learn that human life has a sense and what this sense is" [Hartman, 2018: 32]. Therefore, it can be assumed that the special mission of philosophy today is to help us find the meaning of life by reflecting on how to live it well.

Philosophical reflection on gamification responds to this need. For example, Miguel Sicart wondered whether gamification helps to develop a good life, which he defined as follows: "The good life is the life experienced as a process in which we perform the best of our virtues with the goal of flourishing, of exploring our potential as human beings. That flourishing is not externally determined or rewarded, but is the outcome of a process of internal reflection that leads to increased autonomy as human beings, as well as to the setting of intrinsic goals that we identify as constituting the good life" [Sicart, 2014: 229]. A key component of such a concept of a good life is reflection - if the action is good but unconscious — it does not help the human potential to flourish.

Sicart concluded that it is a common mistake in gamification projects to ignore the need to reflect on action - thus they do not serve the practice of virtues, but only force their realization. He stated that designers should bear in mind that gamification should not only develop skills through exercises, but also that it should develop an autonomous interpretation of these exercises leading to self-reflection and evaluation [Sicart, 2014: 234-237]. Sicart's proposal can be treated more broadly — as a general remark to the creators of technology. They can easily succumb to the temptation of offloading the human being, which leads to taking responsibility for action away from him. Such an approach, though extremely dangerous, can be particularly tempting today.

\subsection{Utopia of gamification}

Meanwhile, games can not only contribute to a good life, but can even form the basis of an ideal life. Such an interpretation can be found in Bernard Suits' theory. He formulated his concept in two theses: "The first is that play is necessary but not sufficient adequately to account for the ideal of existence. The second is that game playing performs a crucial role in delineating that ideal - a role which cannot be performed by any other activity, and without which an account of the ideal is either incomplete or impossible" [Suits, 1978: 166]. He developed these thoughts by describing Utopia — a world in which the development of computerization eliminated the need to work in the broadest sense of instrumental activities. This happened because the various needs on which the current civilization was founded had already been satisfied. The reality shown by Suits is a world based on excess. Of course, in such a world the biggest problem could be boredom, so it is appropriate to assume that people 
would still take up their favourite activities, only voluntarily, and not out of necessity. Such activities would not be fundamentally different from games. If someone wanted to build a house, it would have to be a project so difficult that it would provide satisfaction, but not so much that it could not be completed. Moreover, the aim would not be to build a house itself, but to build one, according to rules that ensure the right amount of satisfaction ${ }^{1}$. In such a world, essentially all productive activities would be a kind of game, providing emotional content related to the pursuit of the goal, and therefore the meaning of life constructed according to individual needs.

Suits predicted the collapse of Utopia, triggered by the problems people would have in accepting that life that makes sense in games would be valuable. The consequence would be to recognize that computers that have eliminated the need to work from life have turned out to be the enemy of mankind. This sad perspective, however, does not make the Utopia impossible to implement ${ }^{2}$. It is worth reminding at this point that the common understanding of utopia as an ideal social system impossible to implement does not fully exhaust the meaning of this notion. This term, used for the first time in the title of Thomas More's book from 1516, has an ambiguous etymology. It can come both from the Greek word outopos (ou — no, topos — place), meaning a place that does not exist, and from eutopia (eu - good, topos — place), meaning a "good place". This ambiguity is characteristic of the overall reflection on the social and political philosophy of ideal systems [Winiarczyk, 2002: 233]. Suits clearly stated that the world he predicted is not only possible, but will actually come.

It can be said that when Suits formulated such a concept in 1978, it was based on the assumption that technological progress, which has always been aimed at increasing productivity, must ultimately eliminate the need to work. At that time it could have been difficult to imagine, although scientists warned against losing their jobs to machines already in the 1820s and then in the 1930s, 1950s and 1970s [Krzysztofek, 2015: 10] ${ }^{3}$. However, these were rather isolated opinions, not yet taken seriously. The voices of contemporary researchers, who more and more often indicate that we are already at the initial stage of the end of work in its current understanding [Rifkin, 1995; Brynjolfsson \& McAffe, 2011], sound different. The saturation with technology of almost every aspect of our lives could not avoid the sphere of work. Kazimierz Krzysztofek wrote: "It is the society most saturated with and dependent on technology in history. It announces a highly automated and robotized production, which poses a threat to living work. The priority will be taken over by "dead work" - the work of machines in which human intelligence is materialized" [Krzysztofek, 2015: 10]. Robots taking people's jobs away from them are one of the most frequently pointed out threats resulting from the development of modern technologies, apart from the loss of control over artificial intelligence or ubiquitous surveillance. Optimists claim that new professions will be created, but they usually point to examples requiring high

\footnotetext{
${ }^{1}$ According to Suits: "play a game is to engage in activity directed towards bringing about a specific state off affairs, using only means permitted by rules, where the rules prohibit more efficient in favour of less efficient means, and where such rules are accepted just because they make possible such activity" [Suits, 1978: 34].

${ }^{2}$ Which was suggested for example by Robert E. Innis, who pointed out the inadequacy of literally reading the statements of Suits [Innis, 2001: 19].

${ }^{3}$ The best-known example of resistance to the taking over of work by machines is, of course, luddism, an English social movement from the beginning of the industrial revolution, whose representatives destroyed the looms.
} 
qualifications or highly developed soft competences. However, there are also many people who do not have either one or the other. Hence, the real threat is the implementation of the cyberpunk dystopia of a highly stratified society, in which a large part of the population is left without occupation. The concept of unconditional basic income is often cited as the solution to economic problems resulting from robotization. However, the problem of widespread disappearance of the sense of getting out of bed every day has not yet been solved, not only by proposals for solutions, but even by a real scientific debate.

However, the awareness of this threat is visible in the works of culture. Jacek Dukaj introduced the notion of "nolensum" in his short story Linie oporu, which reflects the state in which technology is saturated with the ease with which it satisfies all our wishes and we feel a gigantic lack of desires and motivation to realize them. In another text from the same collection, entitled Crux, the author has already directly shown the lower social class, definitively deprived of work by the development of nanotechnology. The biggest problem of its representatives, living thanks to a developed social system, is the absolute lack of sense of existence [Dukaj, 2010]. In this perspective, Suits' work gains a completely new dimension of anticipation of possible social reality. However, it also constitutes a response to its predicted problems, based on all-embracing gamification, understood as a transformation of activities performed in the past from necessity into games - immanent generators of sense of undertaking a given activity.

\section{Conclusion}

Games in their digital version turned out to be a dream laboratory of creating fictional worlds in an unprecedented scale and on many different levels: narrative, technical, artistic, social, and additionally "understandable" both by people and computers.

Gamification, using these possibilities, provides tools that allow to transform various social or cultural phenomena so that they can be described by rules with easily quantifiable criteria of realization. The aim here is to modify those aspects of reality that are not easily reduced to the form in which they are suitable for computer processing.

In the mechanism of gamification one can see the outline of changes that the present digital revolution brings to man. Socio-cultural reality is multiplying more and more, especially as a result of virtualization. The ability to switch efficiently between different dimensions is becoming a basic human skill. Giving meaning to these dimensions is a very important function of gamification, allowing the unknown to be tamed. All this serves the transhumanist project of human evolution through the development of technology. Gamification becomes familiar with the new world that we have created for ourselves. With a virtualized world, where the necessity of continuous development becomes a dogma and where the sense of life may turn out to be the most scarce commodity.

\section{매] References}

Baudrillard, Jean. Simulacra and Simulation. Michigan: The University of Michigan Press, 1994.

Brynjolfsson, Erik, and Andrew McAffe. Race Against the Machine: How the Digital Revolution is Accelerating Innovation, Driving Productivity, and Irreversibly Transforming Employment and the Economy. Lexington (MA): Digital Frontier Press, 2011. 
Bryson, Steve. Virtual Reality: A Definition History - A Personal Essay. 1998. Retrieved 5.05.2018 from: https://pdfs.semanticscholar. org/6256/74418d331cf3388437f0c57d8b56cb0dfd61.pdf

Crawford, Robert. Healthism and the Medicalization of Everyday Life. International Journal of Health Services. Vol. 10, No. 3, 1980: 365-388. https://doi.org/10.2190/3H2H-3XJN3KAY-G9NY

Deterding, Sebastian, Dan Dixon, Rilla Khaled, and Lennart Nacke. From Game Design Elements to Gamefulness: Defining Gamification. Proceedings of the $15^{\text {th }}$ International Academic MindTrek Conference: Envisioning Future Media Environments. 2011: 9-15. https://doi.org/10.1145/2181037.2181040

Dukaj, Jacek. Król bólu. Kraków: Wydawnictwo Literackie, 2010.

Fuchs, Mathias. Predigital Precursors of Gamification. In: Rethinking Gamification. Mathias Fuchs, Sonia Fizek, Paolo Ruffino, Niklas Schrape (ed.). Lüneburg: Meson Press, 2014: 119-140.

Hartman, Jan. Jaki jest sens życia? Niezbędnik Wspótczesny. No. 3, 2018: 30-35.

Hayles, Katherine N. How We Became Posthuman: Virtual Bodies in Cybernetics, Literature, and Informatics. Chicago \& London: The University of Chicago Press, 1999.

Innis, Robert E. Philosophy and the play of life. Focaal - European Journal of Anthropology. Vol. 37, 2001: 121-142.

Rosińska, Zofia. Naukowy zawrót glowy: wywiad z prof. Zofia Rosińska. Interview by Katarzyna Jankowska. Radio broadcast. Polskie Radio Jedynka: 15.04.2015. Retrieved 25.04.2019 from: https://www.polskieradio.pl/7/179/Artykul/1421772, Tracimy-kontaktz-rzeczywistoscia-Ktos-to-przewidzial

Kania, Marta Matylda. Perspectives of the Avatar. Sketching the Existential Aesthetics of Digital Games, Wrocław: Wydawnictwo Naukowe Dolnośląskiej Szkoły Wyższej, 2017, Retrieved 08.08.2018 from: https://opub.dsw.edu.pl/bitstream/11479/296/1/ Perspectives_of_the_Avatar.pdf

Krzysztofek, Kazimierz. Technologie cyfrowe w dyskursach o przyszłości pracy. Studia socjologiczne. No. 4 (219), 2015: 5-31.

LaValle, Steven M., Virtual Reality, Cambridge University Press, 2019, Retrieved 15.05.2019 from: http://vr.cs.uiuc.edu/vrbookbig.pdf

Lévy, Pierre. Becoming Virtual: A Reality in Digital Age. New York, London: Plenum Trade, 1998.

Lévy, Pierre. Drugi potop. In: Nowe media w komunikacji spotecznej w XX wieku. Maryla Hopfinger (ed.). Warszawa: Oficyna Naukowa, 2002: 375-390.

Pico della Mirandola, Giovanni. Mowa o godności człowieka (Oratio de hominis dignitate): Wstęp. In: Filozofia wtoskiego Odrodzenia. Wybrane teksty z historii filozofii. Andrzej Nowicki (ed.). Warszawa: PWN, 1967: 137-142.

Reale, Giovanni. Historia filozofii starożytnej. Vol. I. Lublin: Wydawnictwo KUL, 2005.

Rifkin, Jeremy. The End of Work: The Decline of the Global Labor Force and the Dawn of the Post-market Era. New York: G.P. Putnam's Sons, 1995.

Sicart, Miquel. Playing the Good Life: Gamification and Ethics. In: The Gameful World. Approaches, Issues, Applications. Steffen P. Walz, Sebastian Deterding (ed.). Cambridge (MA): The MIT Press, 2014: 225-244.

Sidey Myoo. Ontoelektronika. Kraków: Wydawnictwo UJ, 2013.

Suits, Bernard. The Grasshopper: Games, Life and Utopia. Toronto: University of Toronto, 1978. 
Winiarczyk, Marek. Utopia antyczna: zarys problematyki. Meander. No 3/4, 2002: 233-254.

Wróblewski, Michał. Nowe szaty healthismu. Self-tracking, neoliberalizm i kapitalizm kognitywny. Acta Universitatis Lodziensis. Folia Sociologica. No 58, 2016: 5-23. https://doi.org/10.18778/0208-600X.58.01

Zawojski, Piotr. Posthumanizm, czyli humanizm naszych czasów. Kultura i Historia. No 32, 2018: 68-76. 